\title{
Job demands and job resources as predictors of teacher motivation and well-being
}

\author{
Einar M. Skaalvik ${ }^{1,2}$ D $\cdot$ Sidsel Skaalvik ${ }^{2}$ \\ Received: 7 February 2018 / Accepted: 2 July 2018 / Published online: 24 August 2018 \\ (c) The Author(s) 2018
}

\begin{abstract}
We analyzed how teacher perception of job demands and job resources in the school environment were related to teacher well-being, engagement and motivation to leave the teaching profession. Participants were 760 Norwegian teachers in grade 1-10. Data were analyzed by means of confirmatory factor analysis and SEM analysis. A second order job demand variable strongly predicted lower teacher well-being, whereas job resources more moderately predicted higher well-being. Teacher wellbeing was in turn predictive of higher engagement and lower motivation to leave the profession. Analysis of primary factors showed that time pressure was the strongest predictor of teacher well-being.
\end{abstract}

Keywords Teacher well-being $\cdot$ Job demands $\cdot$ Job resources $\cdot$ Engagement · Motivation

\section{Introduction and purpose}

A number of recent studies in different countries reveal that teaching is a particularly stressful occupation (Chan 2002; Desrumaux et al. 2015; Hakanen et al. 2006; Johnson et al. 2005; Liu and Onwuegbuzie 2012; Montgomry and Rupp 2005; Stoeber and Rennert 2008). Teacher stress is typically conceptualized as unpleasant emotions resulting from aspects of the work as a teacher (Collie et al. 2012; Kyriacou 1987, 2001; Liu and Onwuegbuzie 2012). Possible consequences of high job demands and long-term teacher stress are reduced teacher self-efficacy (Klassen et al. 2013; Skaalvik and Skaalvik 2016) and reduced teacher well-being, for

Einar M. Skaalvik

einar.skaalvik@ntnu.no

Sidsel Skaalvik

sidsel.skaalvik@ntnu.no

1 NTNU Social Research, Dragvoll Allé 38, 7491 Trondheim, Norway

2 Norwegian University of Science and Technology, Trondheim, Norway 
instance higher levels of burnout (Betoret 2009) and negative affect, depression, and psychosomatic responses (Skaalvik and Skaalvik 2015). These processes may in turn result in lower job satisfaction (Collie et al. 2012; Desrumaux et al. 2015), lower levels of commitment and engagement (Klassen et al. 2013; Skaalvik and Skaalvik 2016), and increased motivation to leave the teaching profession (Skaalvik and Skaalvik 2011a). Moreover, teacher stress may not only result in increased motivation for leaving the profession, but also in actual leaving (Weiss 1999).

Aspects of the work and the work environment that may be stressful are often termed stressors (e.g., Betoret 2006) or job demands (Demerouti et al. 2001). For instance, numerous studies reveal that teacher stress is associated with workload and time pressure (see Sect. 2.1.2). However, teacher motivation and well-being are not only affected by stressors or job demands but have also been shown to be related to positive aspects of the work, which are often termed job resources. For instance, positive relations with colleagues and the school administration as well as the feeling of doing a meaningful job have been shown to be positively related to teachers' engagement and well-being and negatively related to teacher stress (e.g., Collie and Martin 2017; Hakanen et al. 2006; Skaalvik and Skaalvik 2015).

The purpose of this study was to explore how perceived job demands and job resources in the teaching profession predicted teacher well-being, engagement, and motivation to leave the profession. A second purpose was to test if associations between (a) job demands and job resources and (b) engagement and motivation to leave the profession were mediated through teacher well-being.

\section{Theoretical framework}

\subsection{Job demands and job resources}

\subsubsection{Job demands}

The documentation of high teacher stress in studies in several different countries has led researchers to explore aspects of the work and the work environment that may be stressful. As noted, these aspects of the work are termed "stressors" by some researchers and "job demands" by other researchers. We will refer to these aspects of the work as job demands. Job demands which are identified in teacher research include time pressure (also termed work overload), discipline problems (also termed pupil misbehavior), low student motivation, large student diversity, conflicts with colleagues, lack of administrative support, value conflicts, and role ambiguity (Betoret and Artiga 2010; Collie et al. 2012; Fernet et al. 2012, 2013; Friedman 1995; Hakanen et al. 2006; Klassen and Chiu 2010; Kokkinos 2007; Shernoff et al. 2011; Skaalvik and Skaalvik 2011a, 2015).

We included three job demands in the present study: (a) time pressure, (b) discipline problems, and (c) low student motivation. Educational researchers in different countries have reported an increasing workload in the teaching profession and an acceleration of working speed among teachers (Buchanan 2010; Hargreaves 2003; Lindqvist and Nordänger 2006; Skaalvik and Skaalvik 2015; Smithers and Robinson 
2003). Numerous studies have also shown time pressure and discipline problems to be associated with stress, emotional exhaustion, lower levels of commitment and job satisfaction, lower self-efficacy, and motivation to leave the teaching profession (Betoret 2009; Betoret and Artiga 2010; Collie et al. 2012; Fernet et al. 2012, 2013; Hakanen et al. 2006; Skaalvik and Skaalvik 2011a, 2015, 2017a). Time pressure and discipline problems were therefore included as potential job demands in the present study. We also included low student motivation because it was frequently identified as a stressor by teachers in an interview study (Skaalvik and Skaalvik 2015). Also, Skaalvik and Skaalvik (2017a) found that low student motivation was associated with lower teacher self-concept and symptoms of teacher burnout.

\subsubsection{Job resources}

Whereas much of the teacher research has focused on teacher stress, research on teacher engagement and job satisfaction has identified some potential job resources. The job resources explored in previous studies include teacher autonomy, positive and supportive relations with colleagues as well as with the school administration and the parents, perceived fairness, teachers' opportunities for learning and development, value consonance, and collective culture (Collie and Martin 2017; Fernet et al. 2013; Hakanen et al. 2006; Simbula et al. 2011; Skaalvik and Skaalvik 2011a, b).

Four potential job resources were included in the present study: (a) positive and supportive relations with colleagues, (b) supervisory support, (c) the perception of a collective culture at school, and (d) value consonance. Numerous previous studies show that positive and supportive social relations with colleagues and the school administration are associated with engagement and job satisfaction, but also with well-being and lower levels of burnout (Collie and Martin 2017; Fernet et al. 2013; Hakanen et al. 2006; Pines and Aronson 1988; Simbula et al. 2011; Skaalvik and Skaalvik 2011a, 2017a). These studies indicate that positive and supportive social relations, both with colleagues and the school administration, are important job resources that may work as a buffer against burnout and negative affect. Thus, positive and supportive social relations with both colleagues and the school administration may strengthen teacher resilience. A third potential job resource, that is less frequently studied, is what we may term "a collective culture". We conceptualize a collective culture as a common understanding of goals and values among the teachers and between the teachers and the school administration, and as a set of common practices among the teachers (Skaalvik and Skaalvik 2017a). Skaalvik and Skaalvik (2017a) reasoned that a collective culture would reduce conflicts and increase teachers' beliefs about their practices. Supporting this reasoning they found that a collective culture was positively associated with teaching self-concept and job satisfaction and negatively associated with teacher burnout.

Another understudied, but potential job resource that was included in this study is value consonance which may be conceptualized as a dimension of person-environment fit (Skaalvik and Skaalvik 2015). Skaalvik and Skaalvik (2011a, p. 1031) defined value consonance as "the degree to which teachers feel that they share the prevailing norms and values at the school where they are teaching, for instance what 
goals should be pursued, what content should be emphasized, and what educational means and methods should be used." Although both value consonance and collective culture refer to educational values and practices and may overlap, these constructs should be distinguished. Even in a school with a strong collective culture, there may be single teachers who perceive that their values are different from the prevailing values at the school. In an interview study of thirty Norwegian teachers Skaalvik and Skaalvik (2015) concluded that lack of value consonance may be caused by the increasing dependency of the individual teacher on the teacher team and the increasing tendency for micromanagement at schools.

We propose that value consonance may be an important job resource in the teaching profession because many teachers are driven by values, ethical considerations, and intrinsic motivation (Sahlberg 2010). A teacher who feels that the prevailing norms and values at the school are incompatible with her or his own values may experience what Rosenberg $(1977,1979)$ referred to as contextual dissonance. A contextual dissonance may result in a feeling of not belonging, a feeling that one does not fit, that one is out of it, somehow wrong (Rosenberg 1977, 1979). Hence, we expected value consonance to be positively related to teacher well-being. Supporting this expectation, Skaalvik and Skaalvik (2011a) found that value consonance was positively associated with belonging and negatively associated with emotional exhaustion.

\subsubsection{The job demands-resources (JD-R) model}

The job demands-resources (JD-R) model proposes that in all occupations one may distinguish between two categories of work characteristics: job demand and job resources (Demerouti et al. 2001; Bakker and Demerouti 2006; Hakanen et al. 2006). Demerouti et al. (2001) define job demands as "those physical, social, or organizational aspects of the job that require sustained physical or mental effort" (p. 501). Because job demands require sustained effort they are supposed to be associated with physical or psychological costs and may therefore result in emotional exhaustion (Demerouti et al. 2001). According to Demerouti et al. (2001) job resources refer to physical, psychological, social, and organizational aspects of the job that (a) help achieve work goals, (b) reduce job demands or the consequences of job demands, and (c) stimulate personal growth and development.

According to the JD-R model we may distinguish between two relatively independent processes: (a) a health impairment process in which job demands may lead to exhaustion and negative affect and (b) a motivational process in which job resources may increase job satisfaction and engagement (Bakker and Demerouti 2014). The JD-R model also proposes an interaction between job demands and job resources (Bakker and Demerouti 2006). For instance, social support (a job resource) may buffer the negative effect of job demands on teacher well-being and engagement. Thus, based on the JD-R model we may expect that job resources may increase teacher well-being and engagement and reduce teachers' motivation to leave the profession, whereas job demands may decrease teacher well-being and engagement and increase motivation to leave the profession. These expectations 
however, are general and different job demands and job resources may be differently related to possible outcome variables.

Empirical studies provide strong support for the effect of job demands and more moderate support for the effect of job resources. Job demands and job resources are typically represented by single latent variables in these studies. For instance, in a SEM analysis, Hakanen et al. (2006) found that a latent teacher job demand variable indicated by workload, pupil misbehavior, and unfavorable physical environments strongly predicted teacher burnout (beta $=.57$ ). A latent job resource variable indicated by autonomy, information, supervisory support, social climate, and innovative climate was positively but weakly associated with teacher engagement (beta $=.10)$ and moderately and negatively associated with burnout (beta $=-.28$ ). In a study of academic staff, mostly university lecturers and senior lecturers, Boyd et al. (2011) found that job resources indicated by perceived autonomy and fairness were negatively associated with subsequent experiences of strain (beta $=-.21$ ) and positively associated with a subsequent measure of commitment (beta $=.25$ ). Also, in a study of non-teaching employees in a nutrition company, Bakker et al. (2003) found that job demands indicated by workload and reorganization significantly predicted burnout, whereas job resources indicated by autonomy and participating in decision making significantly predicted commitment. In an interesting study of burnout among school board employees, Fernet et al. (2013) found a strong positive direct association between role overload (a job demand) and emotional exhaustion, whereas a moderate negative association between social support (a job resource) and depersonalization was mediated through perceived relatedness.

Although the JD-R model are supported in empirical research there is a need for more research. Some studies have explored relations with either job demand or job resources (e.g., Collie and Martin 2017), however these constructs need to be analyzed together. Several researchers, who include both job demands and job resources, have analyzed how possible outcome variables relate to single latent job demand and job resource variables (e.g., Hakanen et al. 2006) whereas there is a need to study the relative importance of particular job demands and job resources. Also, many studies have included only a couple of job demands and job resources. The present study addresses these problems by including four job resources and three job demands, and by testing two SEM-models where job demands and resources are represented either by second order factors or by primary factors.

\subsection{Teacher well-being}

Associations between (a) job demands and job resources and (b) different possible indicators of teacher well-being have been revealed in several studies. Many studies explore relations with burnout, which may be conceptualized as a measure of teacher well-being. A number of these studies show that job demands are related to higher levels of emotional exhaustion, whereas job resources are related to lower levels of depersonalization (for an overview, see Fernet et al. 2013). These results indicate that a general measure of burnout is not adequate for analyzing the relations between job characteristics and teacher well-being. Other researchers have indicated 
well-being by means of a mixture of variables including both possible causes of well-being, for instance positive social relations at school, and possible effects of well-being, for instance engagement (e.g., Desrumaux et al. 2015).

Teacher well-being was in the present study measured negatively, indicated by (a) emotional exhaustion, (b) depressed mood, and (c) psychosomatic responses. These measures were factor analyzed to make sure that they could be used as indicators of a latent well-being variable. Emotional exhaustion is considered as one of three key dimensions of burnout (Maslach 2003; Maslach et al. 1996). It results from long term work-related stress, which we may conceptualize as unpleasant emotions resulting from aspects of the work. Emotional exhaustion is characterized by low energy and chronic fatigue (Pines and Aronson 1988; Schwarzer et al. 2000; Skaalvik and Skaalvik 2015). Research also shows that emotional exhaustion is associated with work overload (Skaalvik and Skaalvik 2009, 2015), lower motivation (Hakanen et al. 2006), lower job satisfaction (Skaalvik and Skaalvik 2009), and increased intention of leaving the teaching profession (Leung and Lee 2006).

Depressed mood is characterized by sadness, worthlessness, helplessness, and hopelessness (Mahoney et al. 2002; Shen et al. 2014). According to Shen et al. (2014) work-related stress is one risk factor for depressive symptoms. Also, depression may arise when people find themselves in situations that are unacceptable to them and from which they cannot escape (Allan and Gilbert 1997; Skaalvik and Skaalvik 2015).

Teacher stress, which may result from high job demands, may also result in physiological or psychosomatic responses (Kyriacou and Sutcliffe 1979). For instance, Bosma et al. (1998) found that work-related stress was associated with cardiovascular disease and Lundberg (2003) found that stress was related to psychosomatic symptoms like pain in the neck and shoulders. Also, Ritvanen et al. (2006), in a study of female teachers, found that psychosomatic responses like headache, tension, stomach pain, and sleeping disorder increased during periods of high stress.

Based on these findings and reflections we expected that emotional exhaustion would be strongly associated with depressed mood and psychosomatic responses and that these constructs would constitute adequate indicators on a negative latent teacher well-being variable.

\subsection{Engagement}

Work engagement is defined as a positive, fulfilling, work-related state of mind that is characterized by vigor, dedication, and absorption (Bakker et al. 2011; Schaufeli and Bakker 2010). Bakker et al. (2011) particularly emphasize the experience of energy (vigor) and the perception of the work as a significant and meaningful pursuit. Research indicates that teacher engagement is positively associated with teacher self-efficacy and negatively associated with emotional exhaustion (Skaalvik and Skaalvik 2016). Research also shows that work engagement is associated with positive outcomes, for instance lower intentions of leaving the teaching profession (Bakker and Bal 2010; Skaalvik and Skaalvik 2016). 
Whereas some researchers have used work engagement as an indicator of teacher well-being, we conceptualized work-engagement as an outcome of teacher wellbeing. Hence, we expected that teacher engagement would be positively associated with job resources and negatively associated with job demands, and that both these associations would, in part, be mediated through teacher well-being.

\subsection{Motivation to leave the teaching profession (quit)}

Research during the last two decades shows that teacher attrition is a serious problem in many countries (Chang 2009; Hong 2010; Ingersoll 2001; Köber et al. 2005; McDonald 1999). For example, Chang (2009) found that $25 \%$ of beginning teachers in the US left teaching before their third year, and almost $40 \%$ left the profession within the first 5 years. Additionally, many teachers leave the profession before they reach retirement age (McDonald 1999). One reason for teacher attrition is the high level of stress and burnout among teachers (Chang 2009). Supporting the conclusion by Chang (2009), Skaalvik and Skaalvik (2011a) found that teachers' motivation to leave the profession was positively predicted by emotional exhaustion and negatively predicted by job satisfaction. We therefore expected that the motivation to leave the profession would be negatively associated with teacher well-being and engagement.

\subsection{The present study}

The present study was designed to explore how perceived job demands and job resources in the teaching profession predicted teacher well-being, engagement, and motivation to leave the profession. We expected that job resources would be positively associated with teacher well-being. Previous research shows that positive social relations with colleagues and the school administration are associated with well-being, for instance job satisfaction and lower levels of burnout (Collie and Martin 2017; Fernet et al. 2013; Hakanen et al. 2006; Pines and Aronson 1988; Simbula et al. 2011; Skaalvik and Skaalvik 2011a, 2017a). As stated above, we expected that positive and supportive social relations might work as a buffer against burnout and negative affect. We also expected that value consonance and a collective culture would be positively associated with teacher well-being (see Sect. 2.1.2). Furthermore, we expected that job demands would predict lower teacher well-being. For instance, in a review of research, Fernet et al. (2013) found that a number of studies show that job demands are related to higher levels of emotional exhaustion.

Teacher well-being was in this study measured negatively, indicated by emotional exhaustion, depressed mood, and psychosomatic responses. These conditions are energy consuming. Also, teachers who are exhausted, depressed, or suffering from psychosomatic responses may be expected to dwell with their own problems. Therefore, we expect low well-being to be associated with lower levels of engagement and higher motivation to leave the teaching profession. Consequently, we expected that the association between (a) job demands and job resources and (b) engagement and motivation to leave the profession would, at least partly, be mediated through teacher well-being. Additionally, we expected 
that engagement in teaching would lead to stronger motivation to stay in the profession. Hence, we also expected that engagement partly would mediate the association between teacher well-being and motivation to quit.

In accordance with previous studies of the JD-R model, where job demands and job resources are often treated as single latent variables (e.g., Bakker et al. 2003; Demerouti et al. 2001; Hakanen et al. 2006), our expectations and research questions were first explored by means of SEM analyses in which job demands and job resources were represented by second order factors. However, as already noted, different job demands and job resources may differ in how strongly they are related to teacher well-being and engagement. These differences may be masked when analyzing job demands and job resources as single latent variables. An additional purpose of this study was therefore to test which job demands and job resources were significantly, or most strongly, associated with teacher well-being, engagement, and motivation to leave the profession. For this purpose, we conducted analyses of primary job demand and job resource factors.

\section{Method}

\subsection{Participants and procedure}

This study was part of a larger data collection and analysis of teachers' perception of the school goal structure, teacher self-efficacy, and job satisfaction are presented separately (Skaalvik and Skaalvik 2017b). Participants in the study were 760 teachers in elementary school (grade 1-7) and middle school (grade 8-10). The data were collected in April and May 2016. Thirty-one schools were drawn by random from three counties in central Norway and all teachers in those schools were invited to participate. Based on the school statistics $81 \%$ of the teachers at the selected schools participated in the study. Sixty-nine percent of the participants were women. The age ranged from 23 to 68 years with a mean of 44 years and the experiences as teachers ranged from 1 to 47 years with a mean of 15 years.

Prior to the data collection the teachers were informed that the aim of the study was to explore teachers' perceptions of their working conditions and their experiences of working as teachers. More particularly, they were told that we would explore what they might experience as stimulating and motivating but also what they might experience as stressful and energy tapping. They were also informed that participation was voluntary and anonymous. Following advice from the Norwegian Centre for Research Data, the teachers were informed that they consented to participate by filling out and submitting the questionnaire. A period during working hours was set aside for the teachers to fill out the questionnaire at the same time. When the questionnaires were filled out, they were put in envelopes and sealed at the spot to assure the teachers that they were anonymous. 


\subsection{Instruments}

\subsubsection{Job resources}

Supportive colleagues were measured by means of a three-item scale developed by Skaalvik and Skaalvik (2011a): "In educational matters, I can always get good help from my colleagues", "The relations among the colleagues at this school are characterized by friendliness and a concern for each other", and "Teachers at this school help and support each other". Cronbach's alpha was .84. Supervisory support was also measured with a previously tested three-item scale (Skaalvik and Skaalvik 2011a). The items were: "In educational matters, I can always get help and advice from the school leadership", "My relationship with the school leadership is one of mutual trust and respect", and "The school leadership is supportive and praises good work". Cronbach's alpha was .86. We also regarded a collective school culture as an important job resource. We conceptualized a collective school culture as characterized by common goals, values, and practices. The items measuring this construct were: "The teachers and the school administration at this school have a common understanding of the direction in which the school should be developed", "The teachers at this school have a shared perception of goals and means of the school development", and "The teachers at this school practice a common set of norms and rules". Cronbach's alpha for the scale was .78. Value consonance was measured by means of a previously tested three-item "Value consonance scale" (Skaalvik and Skaalvik 2011a). The items were: "My educational values are in accordance with the values which are emphasized at this school", "My colleagues and I have the same opinion about what is important in education", and "I feel that this school shares my view of what constitutes good teaching". Cronbach's alpha for the scale was .80. Responses on all items measuring job resources were given on a 6-point scale from "Completely disagree" (1) to "Completely agree" (6).

\subsubsection{Job demands}

We included three measures of job demands in the study: (a) time pressure, (b) discipline problems, and (c) low student motivation. These variables are previously tested by five, three, and four items (Skaalvik and Skaalvik 2016). Examples of items measuring time pressure are: "Preparation for teaching must often be done after working hours", "Life at school is hectic and there is no time for rest and recovery", and "Meetings, administrative work, and documentation take much of the time that should be used for preparing teaching". Responses were given on a 5-point scale from "Completely disagree" (1) to "Completely agree" (5). Cronbach's alpha for the scale was .83. The items measuring discipline problems were: "My teaching is often disrupted by students who lack discipline", "Some students with behavioral problems make it difficult to carry out lessons as planned", and "Controlling students' behavior takes a lot of time and effort". Responses were given on a 6-point scale from "Completely disagree" (1) to "Completely agree" (6). Cronbach's alpha for the scale was .83. Low student motivation was measured by the following items: "Many of my students show little interest in schoolwork", "Many of my students give up once they meet a challenge", "I find it difficult 
to make all students work seriously with schoolwork", and "Many of my students show little effort at schoolwork". Responses were given on a 6-point scale from "Completely disagree" (1) to "Completely agree" (6). Cronbach's alpha for the scale was .89.

\subsubsection{Teacher well-being}

Emotional exhaustion was measured by means of a short six-item Norwegian version of the emotional exhaustion dimension of the Maslach Burnout Inventory-Educators Survey (see Skaalvik and Skaalvik 2011a). The participants rated statements indicating that their work made them feel emotionally drained or exhausted. Responses were given on a 6-point scale from "Completely disagree" (1) to "Completely agree" (6). Cronbach's alpha for the scale was .91. Depressed mood was measured with a fiveitem scale developed for this study. The items were: "During this school year, to what extent have you been bothered by: (a) Feeling of hopelessness, (b) Anxiety, (c) Depression, (d) Feeling of uselessness, and (e) Worry." Responses were given on a 4-point scale from "Not at all bothered" (1) to "Very much bothered" (4). Cronbach's alpha for the scale was .85. Psychosomatic responses were measured with a five-item scale. The items were: "During this school year, to what extent have you been bothered by: (a) Pain in your neck, back, or shoulders, (b) Digestion problems, (c) Headache, (d) Dizziness, and (e) Sleeping problems. Responses were given on a 4-point scale from "Not at all bothered" (1) to "Very much bothered" (4). Cronbach's alpha for the scale was .69.

\subsubsection{Engagement}

Engagement for teaching was measured by means of the short nine-item version of the Utrecht Work Engagement Scale (Schaufeli et al. 2006). The scale measures three dimensions of engagement: vigor, dedication, and absorption. An example of an item is: "At my work, I feel bursting with energy" (vigor). Responses were given on a 7-point scale from "Never (1) to "Every day" (7). Cronbach's alpha for the scale was .89.

\subsubsection{Motivation to leave the teaching profession}

Motivation to leave the teaching profession (quit) was measured with a three-item Motivation to leave scale (Skaalvik and Skaalvik 2011a, 2016). The items were: "I wish I had a different job to being a teacher", "If I could choose over again I would not be a teacher" and "I often think of leaving the teaching profession". Responses were given on a 6-point scale from "Completely disagree" (1) to "Completely agree" (6). Cronbach's alpha for the scale was .90 .

\subsection{Data analysis}

The first step in the analysis was to test a series of measurement models by means of confirmatory factor analyses using the AMOS 25 program. We then tested two SEM models letting job resources and job demands predict a second order low well-being variable which in turn predicted engagement and motivation to quit (see Sect. 4). 
To assess the model fit, we used well-established indices, such as CFI, IFI, TLI, and RMSEA. For the CFI, IFI, and TLI indices, values greater than .90 are typically considered acceptable, and values greater than .95 indicate a good fit of the data (Byrne 2001; Hu and Bentler 1999). For well-specified models, an RMSEA of .06 or less reflects a good fit (Hu and Bentler 1999; Tabachnick and Fidell 2007).

\section{Results}

\subsection{Zero order correlations}

Zero order correlations between the study variables as well as statistical means and standard deviations are shown in Table 1. All correlations between the four job resources were positive and ranged from $r=.438$ to $r=.590$. Also, the correlations among the three indicators of low well-being were positive and ranged from $r=.458$ to $r=.637$. The correlations among the three job demands were weaker, ranging from $r=.107$ to $r=.268$. With one exception, emotional exhaustion, depressed mood, and psychosomatic responses correlated negatively with all job resources and positively with all job demands. The exception was low student motivation, which was unrelated to psychosomatic responses. All the three measures of low well-being correlated negatively with engagement and positively with motivation to quit. Gender was weakly related to all study variables. However, we should note that female teachers reported more psychosomatic responses than male teachers $(r=-.26)$.

\subsection{Factor analyses}

We tested three measurement models of the perceived school context variables (job demands and resources) by means of confirmatory factor analyses. Model 1 defined job demands and job resources as seven correlated primary factors: three job demands (time pressure, discipline problems, and low student motivation) and four job resources (supportive colleagues, supervisory support, collective school culture, and value consonance). Model 2 defined a second order job demand variable indicated by discipline problems, time pressure, and low student motivation and a second order job resource variable indicated by supportive colleagues, supervisory support, collective culture, and value consonance. Model 3 defined three primary job demand factors and a second order job resources factor. This model was tested because the strong inter-correlations between the job resources indicated that a second order job resources variable would fit the data well, whereas the job demands were weakly correlated (see Table 1).

We also tested two measurement models of teacher well-being. Model 4 defined three primary low well-being factors: physical and emotional exhaustion, depressed mood, and psychosomatic responses, whereas Model 5 defined a second order low well-being variable indicated by the three primary factors.

The results of these factor analyses are shown in Table 2 . All three models testing job demands and job resources had good fit to the data and the differences in $\chi^{2} / d f$, 


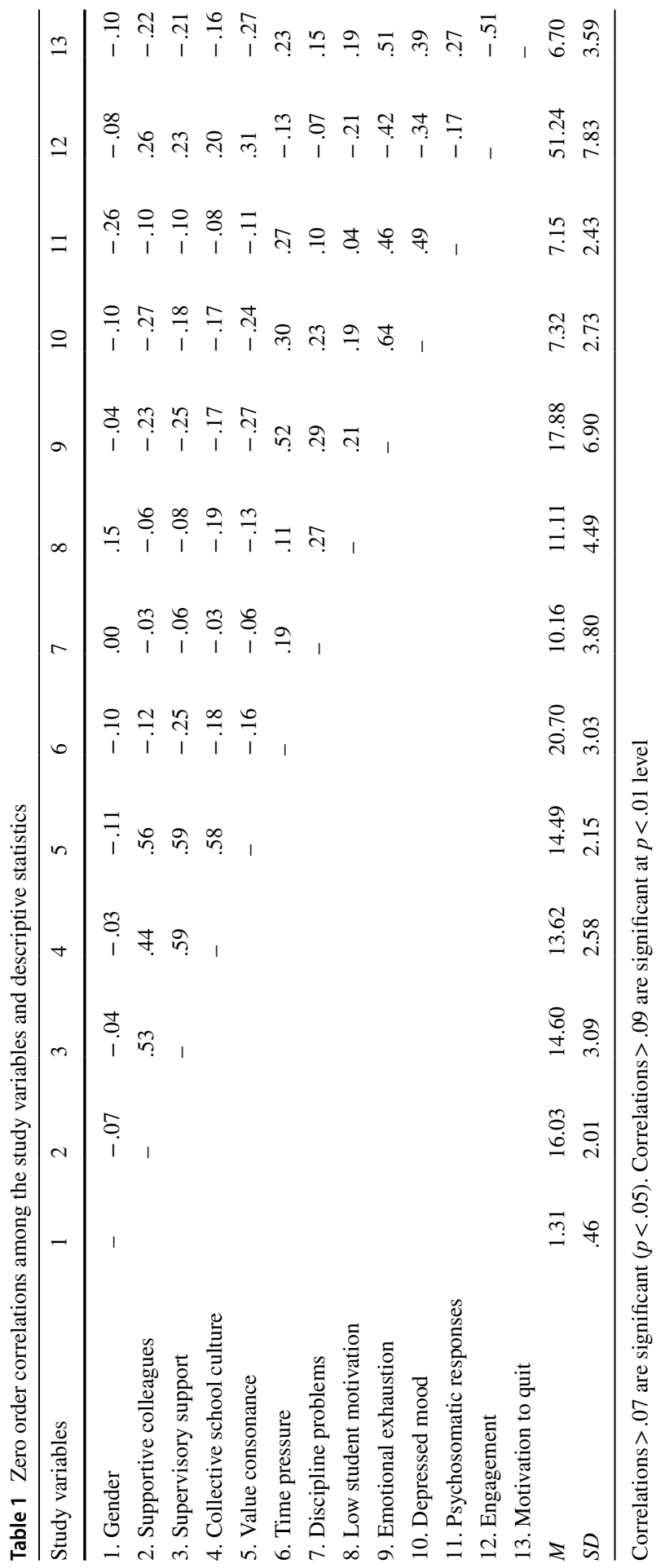


CFI, TLI, and RMSEA were small. Hence, all the three models representing job demands and job resources were adequate as a basis for SEM analysis.

Model 4 and 5, testing measurement models of negative well-being, had very good and identical fit to the data. Because model 5 was the more parsimonious model and because all primary factors loaded strongly on the second order factor, we decided to test SEM models in which low well-being was defined by a second order factor.

We then tested two measurement models including all variables in the study except gender. Teacher well-being was in these models represented by a latent variable as they are also in the SEM analysis. With the exception of well-being Model 6 tested primary factors only, whereas Model 7 tested second order job demand and job resource factors. As shown in Table 2 the two models had good fit to the data and the differences in $\chi^{2} / d f$, CFI, TLI, and RMSEA were small. The correlations among the latent variables in Model 6 are shown in Table 3. The correlations between (a) the primary job demand and job resource factors and (b) negative wellbeing, engagement, and motivation to quit were moderate. These correlations indicated that the perceived school context variables (demands and resources) and the possible outcome variables (well-being, engagement, motivation to quit) could be treated as separate variables. The correlations among the four job resource factors were moderate to strong, ranging from .48 to .69 . Therefore, because of possible problems due to collinearity the results of SEM analysis including job resources as primary factors should be verified in future research.

\subsection{SEM analyses}

The relations between the variables were further analyzed by means of SEM analysis for latent variables. We first tested a model with job resources, job demands,

Table 2 Examination of measurement models

\begin{tabular}{|c|c|c|c|c|c|c|}
\hline Model & $\chi^{2}$ & $d f$ & $\chi^{2} / d f$ & $C F I$ & $T L I$ & RMSEA \\
\hline $\begin{array}{l}\text { Measurement model } 1 \\
\text { Job demands and job resources_-primary factors }\end{array}$ & 688.313 & 232 & 2.967 & .951 & .937 & .051 \\
\hline $\begin{array}{l}\text { Measurement model } 2 \\
\text { Job demands and job resources—second order model }\end{array}$ & 766.832 & 249 & 3.130 & .944 & .933 & .053 \\
\hline $\begin{array}{l}\text { Measurement model } 3 \\
\text { First order job demands and second order job resources }\end{array}$ & 746.015 & 243 & 3.070 & .946 & .933 & .052 \\
\hline $\begin{array}{l}\text { Measurement model } 4 \\
\text { Negative well-being-primary factors }\end{array}$ & 211.380 & 75 & 2.818 & .974 & .958 & .049 \\
\hline $\begin{array}{l}\text { Measurement model } 5 \\
\text { Negative well-being second order model }\end{array}$ & 211.380 & 75 & 2.818 & .974 & .958 & .049 \\
\hline $\begin{array}{l}\text { Measurement model } 6 \\
\text { First order job demands, job resources, engagement, } \\
\text { and motivation to quit and second order well-being }\end{array}$ & 1587.048 & 584 & 2.718 & .934 & .921 & .048 \\
\hline $\begin{array}{l}\text { Measurement model } 7 \\
\text { Second order job demand, job resource, and well-being } \\
\text { and first order engagement and motivation to quit }\end{array}$ & 1721.118 & 612 & 2.812 & .927 & .916 & .049 \\
\hline
\end{tabular}


Table 3 Correlations among latent variables in Model 6 (see Table 2)

\begin{tabular}{lllllllllll}
\hline Study variables & 1 & 2 & 3 & 4 & 5 & 6 & 7 & 8 & 9 & 10 \\
\hline 1. Supportive colleagues & - & .58 & .48 & .63 & -.11 & -.04 & -.07 & -.29 & .29 & -.24 \\
2. Supervisory support & & - & .69 & .68 & -.28 & -.07 & -.08 & -.28 & .26 & -.23 \\
3. Collective school culture & & & - & .66 & -.20 & -.03 & -.21 & -.21 & .22 & -.18 \\
4. Value consonance & & & - & -.19 & -.07 & -.15 & -.32 & .36 & -.31 \\
5. Time pressure & & & & - & .21 & .17 & .62 & -.19 & .27 \\
6. Discipline problems & & & & & - & .30 & .32 & -.12 & .15 \\
7. Low student motivation & & & & & & - & .27 & -.22 & .21 \\
8. Low teacher well-being & & & & & & & - & -.55 & .58 \\
9. Engagement & & & & & & & & & & -.54 \\
10. Motivation to quit & & & & & & & & & & \\
\hline
\end{tabular}

and low well-being as second order factors and engagement and motivation to quit as first order factors (Structural model 1, Fig. 1). There were two reasons that we first tested a model with second order variables. Firstly, most studies of the JD-R model have tested job demands and job resources as single latent variables. By testing a model with second order job demand and job resource variables we were able to compare the pattern of results with previous studies. More specifically, we could test the general expectations that negative teacher well-being would be strongly and positively predicted by the job demands and moderately and negatively predicted by the job resources. In the SEM model, we also included gender as an endogenous variable. The model had acceptable fit to the data $\left(\chi^{2}(1249, N=760)=3322.025, p<.001, \chi^{2} / d f=2.660, \mathrm{RMSEA}=.047\right.$, $\mathrm{IFI}=.901, \mathrm{CFI}=.902, \mathrm{TLI}=.891)$.

Figure 1 shows a strong positive association between job demands and low well-being (beta $=.85$ ) and a moderate negative association between job resources and low well-being (beta $=-.23$ ). The job demands and resources included in this study explained $78 \%$ of the variance in teacher well-being. These results reveal that the perceived job demands included in this study strongly predict a lack of wellbeing, whereas the perceived job resources included in the study predict higher levels of well-being. However, the association between job resources and well-being was moderate. These findings confirm previous studies of the JD-R model where job demands and job resources were represented by single latent variables (e.g., Hakanen et al. 2006).

Low well-being was predictive of lower engagement (beta $=-.46$ ) and higher motivation to quit (beta $=.55$ ). Low well-being was also indirectly related to motivation to quit, mediated through lower engagement. We found no direct effect of job demands on either engagement or motivation to quit. However, Fig. 1 shows a small direct association between job resources and engagement (beta $=.20$ ).

We found only few and small differences between male and female teachers. The analysis revealed a small tendency that female teachers perceived job resources more positively than their male colleagues (beta $=-.09$ ). They also reported higher levels of engagement (beta $=-.09)$ and lower motivation to quit (beta $=.11)$. 


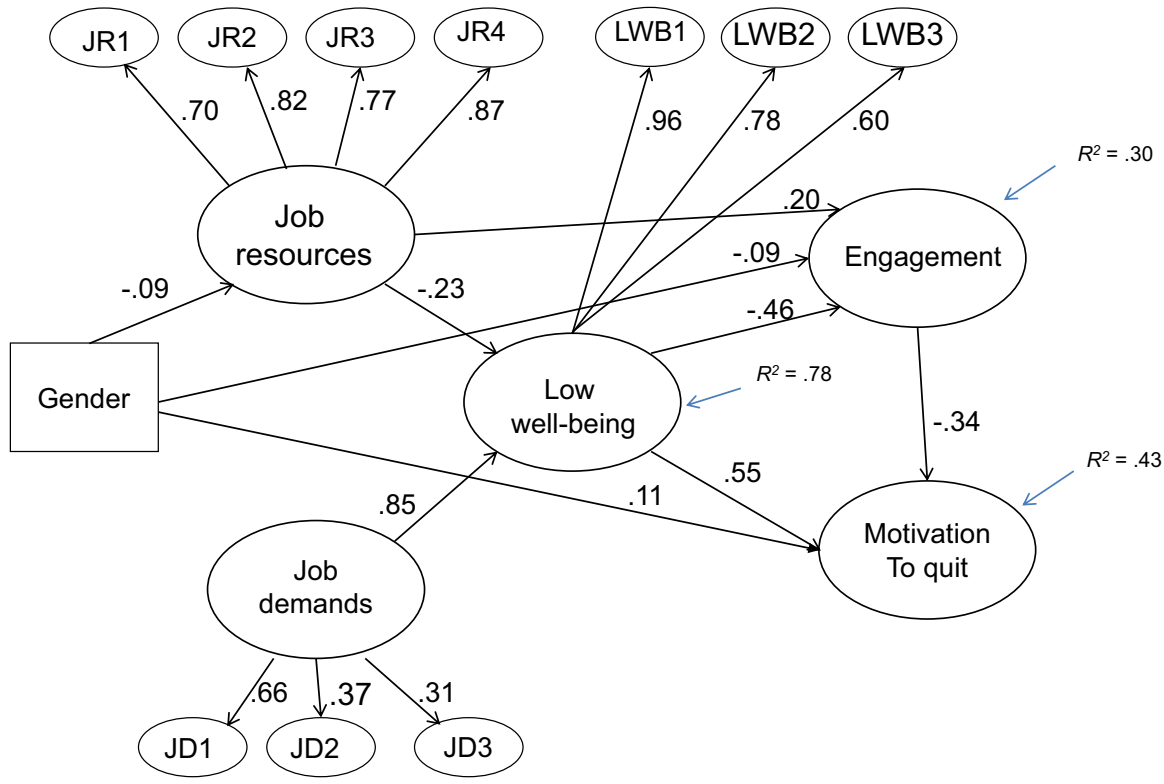

Fig. 1 Structural model 1 of relations between gender, job resources, job demands, low teacher wellbeing, engagement, and motivation to quit. Job resources, job demands, and low teacher well-being are represented by second order factors $(J R 1=$ supportive colleagues, JR $2=$ supervisory support, JR3 = collective culture, JR4 = value consonance, JD1 = time pressure, JD2=discipline problems, JD3=low student motivation, LWB1 = emotional exhaustion, LWB2 = depressed mood, and LWB3 = psychosomatic responses). Standardized regression weights are reported and non-significant regression weights are not included in the figure

As noted above, different job demands and job resources may differ in how strongly they are related to teacher well-being and engagement. These differences may be masked when analyzing job demands and job resources as single latent variables, as is often done in studies of the JD-R model. An additional purpose of this study was therefore to test which job demands and job resources were significantly, or most strongly associated with teacher well-being, engagement, and motivation to leave the profession. For this purpose, we tested a second SEM model in which job demands and resources were represented by primary factors (Fig. 2). Because gender was only weakly and negligibly related to the other study variables (see Table 1 and Fig. 1), the primary job demand and job resource factors were included as correlated exogenous variables and the model did not include gender. The model, which is presented in Fig. 2, had acceptable fit to the data $\left(\chi^{2}(1184, N=760)=2999.167, p<.001, \chi^{2} / d f=2.533, \mathrm{RMSEA}=.045\right.$, $\mathrm{IFI}=.912, \mathrm{CFI}=.913, \mathrm{TLI}=.901)$.

The analysis clearly showed that time pressure was the strongest negative predictor of well-being (beta $=.53$ ), whereas discipline problems and low student motivation were weakly related to teacher well-being (both betas $=.14$ ). Moreover, time pressure was directly related to teacher engagement (beta $=.23$ ). Our 


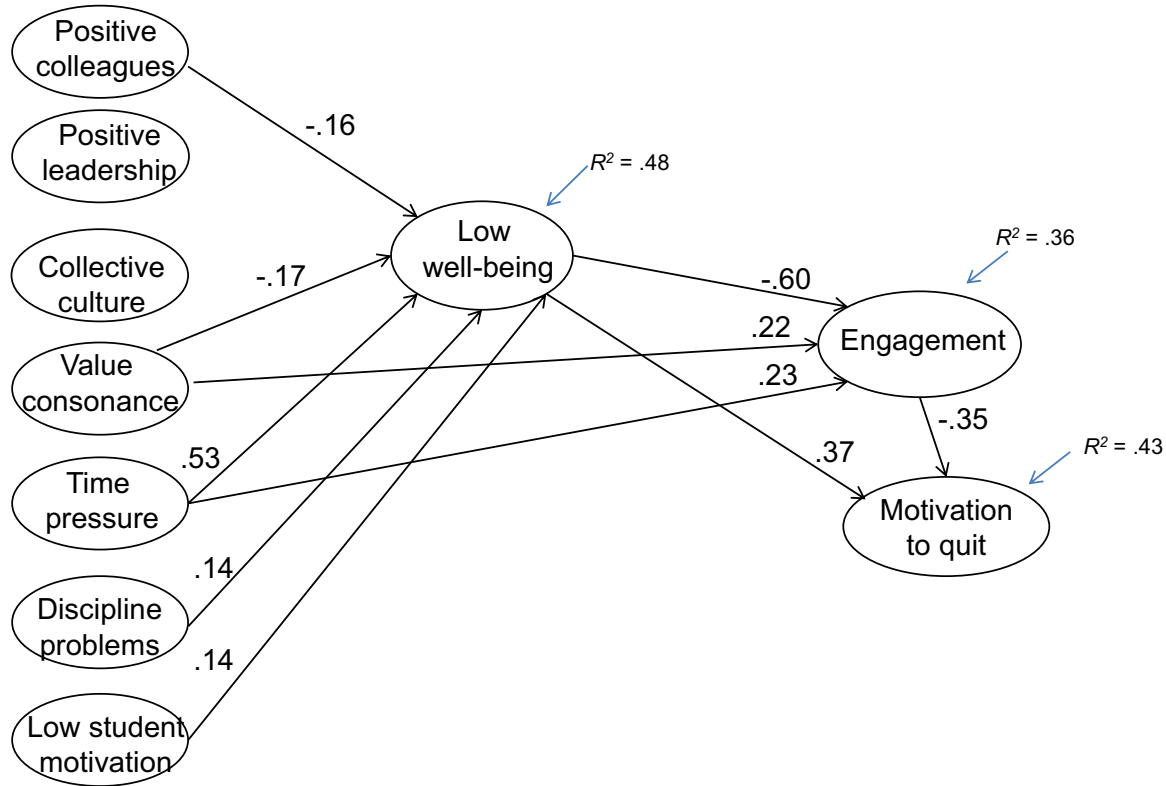

Fig. 2 Structural model 2 with job demands and job resources represented by primary factors. Standardized regression weights are reported and non-significant regression weights are not included in the figure

interpretation of this relation is that the most engaged teachers spend most time preparing for instruction and therefore experience higher time-pressure. Two of the job resources, supportive colleagues and value consonance, were predictive of higher teacher well-being (beta $=-.16$ and -.17 , respectively), whereas supportive leadership and collective culture were not significantly related to well-being. Value consonance was also directly associated with engagement (beta $=.22$ ), whereas none of the other job resources were directly related to engagement. No direct relations were found between the primary job resource and job demand factors and motivation to leave the profession.

\section{Discussion and conclusions}

The aim of this study was to explore how perceived job demands and job resources in the teaching profession predicted teacher well-being, engagement, and motivation to leave the profession. A second purpose was to test if associations between (a) job demands and job resources and (b) engagement and motivation to leave the profession were mediated through teacher well-being. We measured teachers' perceptions of four job resources (supportive colleagues, supervisory support, collective school culture, and value consonance) and three job demands or stressors (time pressure, discipline problems, and low student motivation). We analyzed two SEMmodels, one in which job demands and job resources were represented by second order factors (Model 1, Fig. 1) and one in which job demands and job resources 
were represented by primary factors (Model 2, Fig. 2). Teacher well-being was in both models represented by a latent variable indicated by emotional exhaustion, depressed mood, and psychosomatic responses.

\subsection{Analysis of Model 1}

Analysis of job demands and job resources as second order factors (Fig. 1) revealed that the job demands included in the study strongly predicted lower teacher wellbeing, whereas the job resources that we included moderately predicted higher wellbeing. The job resources were also directly associated with engagement. Thus, two of the expectations derived from the JD-R model were supported. According to the JD-R model we may discriminate between two relatively independent processes: (a) a health impairment process in which job demands may lead to exhaustion and lower well-being and (b) a motivational process in which job resources may increase job satisfaction and engagement (Bakker and Demerouti 2014). These findings are in accordance with several previous analyses where job demands and job resources are treated as single latent variables (see Sect. 2.1.3).

As noted above, teacher well-being was more strongly related to job demands than to job resources. This result supports findings in previous research where job demands and job resources were represented by single latent variables (e.g., Hakanen et al. 2006). A possible explanation of this finding is that the devastating effect of job demands on well-being is stronger that the buffering effect of job resources. However, it is important to note that the total positive effect of job resources on engagement was quite similar in strength to the negative effect of job demands.

Model 1 also revealed the importance of teacher well-being for teacher engagement. Moreover, the association between job demands and engagement was mediated through teacher well-being. A possible explanation is that job demands or stressful working environments lead to increased emotional exhaustion, depressed mood, and psychosomatic responses which again deprive teachers of their engagement. Underlying this explanation is the understanding that it is not job demands in themselves that deprive teachers of their engagement, but job demands that the individual teacher is not able to cope with. This explanation is in accordance with a definition of teacher stress as the result of a mismatch between job demands and the teacher's ability to cope with the demands (e.g., Hakanen et al. 2006). Accordingly, teachers will differ in their responses to the same job demands (see Skaalvik and Skaalvik 2017d). The association between job resources and engagement was also partly mediated through teacher well-being. However, this association was primarily a direct one.

As expected, the association between teacher well-being and motivation to leave the profession was partly a direct one and partly mediated through teacher engagement. We suggest that low well-being may result in motivation to leave the teaching profession for two reasons. First, teachers who associate the development of exhaustion, depressed mood and psychosomatic responses with the working environment at school, will likely be motivated for changing their working environment-for 
moving to another school or for leaving the profession altogether. Second, other teachers may be motivated to leave the profession because exhaustion, depressed mood, or psychosomatic responses results in a loss of engagement. We propose that when a teacher loose engagement he or she will be more motivated to leave the profession. The reason for this is that teachers are typically driven by values, ethical considerations, and intrinsic motivation (Sahlberg 2010; Skaalvik and Skaalvik $2011 \mathrm{a}, \mathrm{b}$ ) and are motivated to contribute to children's development and to make a difference in children's lives (Guarino et al. 2006; Scott et al. 2001; Watt and Richardson 2008). Therefore, many teachers continue in the profession even though they report severe emotional exhaustion, psychosomatic responses, and depressed mood (Skaalvik and Skaalvik 2015, 2017d). These teachers are driven by their engagement for teaching. However, if emotional exhaustion, psychosomatic responses, and depressed mood deprive them from their engagement they may no longer see any reason to continue in the teaching profession.

\subsection{Analysis of Model 2}

Different job demands and job resources may differ in how strongly they are related to teacher well-being, engagement, and motivation to quit. Therefore, one purpose of this study was to test which job demands and job resources were significantly, or most strongly associated with teacher well-being, engagement, and motivation to leave the profession. For this purpose, we conducted a second analysis of primary job demand and job resource factors. The need to analyze a second model with primary factors was also actualized by the fact that the three primary job demand factors loaded quite unequally on the second order job demand factor. Time pressure was the strongest indicator of job demands, whereas discipline problems and low student motivation loaded more moderately on the second order factor. These results are in accordance with a finding by Skaalvik and Skaalvik (2017a), showing that time pressure correlated only moderately with discipline problems and low student motivation in a sample of teachers in senior high school.

The alternative model representing job demands and resources by primary factors (Fig. 2) revealed that time pressure was the far strongest predictor of low well-being (beta $=.53$ ), whereas discipline problems and low student motivation were weakly related to teacher well-being (betas $=.14$ ). These results support previous research showing that time pressure predicts emotional exhaustion more strongly than discipline problems (Skaalvik and Skaalvik 2011a, b, 2017c). A possible explanation of the weak associations between discipline problems and teacher well-being and between low student motivation and teacher well-being is that both discipline problems and low student motivation add to the teachers' workload. Hence, part of the effect of discipline problems and low student motivation on teacher well-being may in the SEM model appear as an effect of time pressure. This explanation is supported by moderate correlations between discipling problems and teacher well-being and between low student motivation and teacher well-being (see Table 3). The correlations were .32 and .27 , respectively. 
Only two of the job resources, value consonance and positive and supporting relations with colleagues, were significantly related to teacher well-being. A particularly interesting finding was also that value consonance was both directly and indirectly associated with higher engagement. The indirect association was mediated through higher well-being. Moreover, value consonance was the only job resource that was directly related to engagement.

Due to a potential collinearity problem these results need to be verified in future research. Nevertheless, a hypothesis for future research is that, in the teaching profession, value consonance is a particularly important job resource which may increase teacher well-being as well as engagement and motivation to continue in the teaching profession. In accordance with Skaalvik and Skaalvik (2011a, b) we defined value consonance as the degree to which teachers feel that they share the prevailing norms and values at the school where they are teaching. Value consonance may be particularly important for teachers' well-being and motivation because teachers are typically driven by values, ethical considerations, and intrinsic motivation (Sahlberg 2010; Skaalvik and Skaalvik 2011a, b). Although teachers may differ in what goals and values they pursue, research reveals that a widespread motive for teaching is to contribute to children's development and to make a difference in children's lives (Guarino et al. 2006; Scott et al. 2001; Watt and Richardson 2008). Moreover, in their daily teaching and classroom management teachers represent and communicate values (Skaalvik and Skaalvik 2011a). We therefore suggest that educational goals and values are important elements of the teacher identity. Value consonance may be positively related to teacher well-being and engagement for two main reasons. First, a teacher who shares the prevailing norms and values at school will be more likely to feel that he or she belong, whereas a teacher who do not share the prevailing norms and values at school may be in a dissonant context (Rosenberg 1977). As described by Rosenberg (1977) this may lead to a feeling of not belonging. Second, depending on the school culture, teachers who do not share the prevailing norms and values at school may feel the pressure to change their practices in a direction that is not compatible with their personal values. These reflections are supported by a few studies showing that value consonance is positively associated with teachers' job satisfaction and feeling of belonging (Skaalvik and Skaalvik 2011a, b) and a study showing that value dissonance is associated with lower teacher self-efficacy and lower engagement (Skaalvik and Skaalvik 2016).

A finding of note was also that positive and supportive relations with colleagues significantly predicted higher teacher well-being. This finding supports previous research showing that supportive social relations with colleagues are associated with teacher well-being (see Sect. 2.1.2). This finding may be understood in terms of selfdetermination theory emphasizing the need for recognition and belonging (Deci and Ryan 2000). Recognition and belonging is in this theory seen as a basic human need that is necessary for well-being and human functioning. An alternative explanation is offered by Collie and Martin (2017) who found that the association between teachers' perception of principal support and teacher well-being partly was mediated through teachers' adaptability. These researchers explain that teachers are exposed to a number of changes and suggest that being able to respond adequately to changes (adaptability) is an important requirement for teachers functioning and well-being. 
Receiving social support, in the present study from colleagues, may according to this perspective strengthen teachers' adaptability. Such a process was also described in a study of senior teachers showing higher adaptability among teachers who supported each other and learned from each other (Skaalvik and Skaalvik 2017d).

\subsection{General discussion}

Although this study indicates that value consonance may be particularly important for teachers' well-being and motivation, we should note that all job resources included in this study are strongly correlated. A possible interpretation of these correlations is that positive and supportive social relations, collective culture, and value consonance both overlap and affect each other in a reciprocal manner. For instance, a positive and supportive relationship with colleagues may lead to a more open communication of values and thereby also to a more common understanding of goals and values. In turn, the development of common goals and values will likely affect social relations among the colleagues positively.

When seen together, Model 1 and 2 illustrate the importance of testing models with both second order factors and primary factors. Model 1 clearly illustrates that job demands in the teaching profession may have devastating effects on teacher wellbeing, and through lower well-being on teacher engagement and motivation to leave the teaching profession. However, this model might mask the differential association between teacher well-being and different job demands. In contrast, the strength of Model 2 is that it shows the relative impact of different job demands. Hence, the choice of structural equation model (or models) should be driven by theoretical analysis and the purpose of the study as well as by the fit of the measurement models.

Our analyses support the JD-R model in that both the proposed health impairment and the motivational processes are evidenced. Also, the analyses clearly indicate that these processes are interrelated. Our results also indicate that the impact of job demands on teacher wellbeing is stronger than the impact of job resources. This supports a conclusion drawn by Hakanen et al. (2006), that the health impairment process is more prominent than the motivational process. This study also demonstrates that, in future research of the JD-R model, it is important not only to study job demands and job resources as single latent or second order factors, but to analyze primary factors to study the impact of different job demands and job resources on a variety of outcome variables.

A practical implication of this study is that, although previous research shows that there are many job demands in the teaching profession (Shernoff et al. 2011; Skaalvik and Skaalvik 2015), educational administers should pay particular attention to reducing the workload and time pressure in the profession. As previously noted, several researchers have reported an increasing workload and an acceleration of working speed among teachers (Buchanan 2010; Hargreaves 2003; Lindqvist and Nordänger 2006; Smithers and Robinson 2003). The present study indicates that this may have become the most serious job demand in the teaching profession. This study also highlights the importance of value consonance for teachers and possibly in all caring professions. When working with, and caring for people, like teachers 
do, values become accentuated and acting counter to one's personal values can be experienced as extremely stressful. A practical implication is therefore that goals, values, and practices should be discussed openly in the teacher collegium and changes and decisions should be both discussed and motivated.

This study has several limitations. It was designed as a cross-sectional study. Readers should therefore be careful not to draw firm conclusions about casual relations. Based on the JD-R model we analyzed SEM models in which perceived job resources and job demands predicted teacher well-being and engagement. However, these relations may be reciprocal. For instance, teachers who are exhausted or depressed tend to be less efficient and may therefore perceive stronger time pressure. They may also have less patience with students and have less energy to motivate students for schoolwork. In contrast, teachers who score high on well-being may be more energetic, seek social relations more actively, and therefore perceive the social environment as more supportive. We therefore call for longitudinal studies to explore causal relations. We should also note that in this study job resources were limited to what we conceptualize as indicators of a supportive social climate. Moreover, we measured only three job demands. Other job resources and job demands need to be included in future research, for instance, job control or autonomy (a job resource) and conflicts with parents (a job demand). We may also speculate that stressors that interfere with the teaching process, for instance discipline problems, have stronger immediate devastating effects on teacher self-efficacy, their beliefs that they are able to achieve important educational goals, than on teacher well-being. Thus, there is a need to study associations between different possible job demands and different possible outcome variables.

Acknowledgements This research was supported by a Grant from the Union of Education Norway.

\section{Compliance with ethical standards}

Conflict of interest The authors declare that they have no conflict of interest.

Ethical approval The study was conducted in line with the ethical research guidelines and approved by the Norwegian Centre for Research Data (NSD) which serves as a national ethical research committee.

Open Access This article is distributed under the terms of the Creative Commons Attribution 4.0 International License (http://creativecommons.org/licenses/by/4.0/), which permits unrestricted use, distribution, and reproduction in any medium, provided you give appropriate credit to the original author(s) and the source, provide a link to the Creative Commons license, and indicate if changes were made.

\section{References}

Allan, S., \& Gilbert, P. (1997). Submissive behavior and psychopathology. British Journal of Clinical Psychology, 36, 467-488. https://doi.org/10.1111/j.20448260.1997.tb01255.x.

Bakker, A. B., Albrecht, S. L., \& Leiter, M. P. (2011). Key questions regarding work engagement. European Journal of Work and Organizational Psychology, 20, 4-28. https://doi.org/10.1080/13594 32X.2010.485352. 
Bakker, A. B., \& Bal, P. M. (2010). Weekly work engagement and performance: A study among starting teachers. Journal of Occupational and Organizational Psychology, 83, 189-206. https://doi. org/10.1348/096317909X402596.

Bakker, A. B., \& Demerouti, E. (2006). The job demands-resources model: State of the art. Journal of Managerial Psychology, 22, 309-328. https://doi.org/10.1108/02683940710733115.

Bakker, A. B., \& Demerouti, E. (2014). Job demands-resources theory. In P. Y. Chen \& C. L. Cooper (Eds.), Wellbeing: A complete reference guide, volume III, work and wellbeing (pp. 37-64). Chichester: Wiley.

Bakker, A. B., Demerouti, E., de Boer, E., \& Schaufeli, W. B. (2003). Job demands and job resources as predictors of absence duration and frequency. Journal of Vocational Behavior, 62, 341-356. https:// doi.org/10.1016/S0001-8791(02)00030-1.

Betoret, F. D. (2006). Stressors, self-efficacy, coping resources, and burnout among secondary school teachers in Spain. Educational Psychology, 26, 519-539. https://doi.org/10.1080/014434105003424 92.

Betoret, F. D. (2009). Self-efficacy, school resources, job stressors and burnout among Spanish primary and secondary school teachers: A structural equation approach. Educational Psychology, 29, 45-68. https://doi.org/10.1080/01443410802459234.

Betoret, F. D., \& Artiga, A. G. (2010). Barriers perceived by teachers at work, coping strategies, self-efficacy and burnout. The Spanish Journal of Psychology, 13, 637-654. https://doi.org/10.1017/S1138 741600002316.

Bosma, H., Peter, R., Siegrist, J., \& Marmot, M. (1998). Two alternative job stress models and the risk of coronary heart disease. American Journal of Public Health, 88, 68-74. https://doi.org/10.2105/ AJPH.88.1.68.

Boyd, C. M., Bakker, A. B., Pignata, S., Wineffield, A. H., Gillespie, N., \& Stough, C. (2011). A longitudinal test of the job demands-resources model among Australian university academics. Applied Psychology: An International Review, 60, 112-140. https://doi.org/10.1111/j.1464-0597.2010.00442 9.x.

Buchanan, J. (2010). May I be excused? Why teachers leave the profession. Asia Pacific Journal of Education, 30, 199-211. https://doi.org/10.1080/02188791003721952.

Byrne, B. M. (2001). Structural equation modelling with AMOS. Basic concepts, applications, and programming. Mahwah, NJ: Lawrence Erlbaum Ass.

Chan, D. (2002). Stress, self-efficacy, social support, and psychological distress among prospective teachers in Hong Kong. Educational Psychology, 22, 557-570. https://doi.org/10.1080/0144341022 000023635.

Chang, M. L. (2009). An appraisal perspective of teacher burnout: Examining the emotional work of teachers. Educational Psychology Review, 21, 193-218. https://doi.org/10.1007/s10648-009-9106-y.

Collie, R. J., \& Martin, A. J. (2017). Teachers' sense of adaptability: Examining links with perceived autonomy support, teachers' psychological functioning, and students' numeracy achievement. Teaching and Teacher Education, 55, 29-39. https://doi.org/10.1016/j.lindif.2017.03003.

Collie, R. J., Shapka, J. D., \& Perry, N. E. (2012). School climate and social-emotional learning: Predicting teacher stress, job satisfaction, and teaching efficacy. Journal of Educational Psychology, 104, 1189-1204. https://doi.org/10.1037/a0029356.

Deci, E. L., \& Ryan, R. M. (2000). The "what and "why" of goal pursuits. Human needs and the selfdetermination of behavior. Psychological Inquiry, 11, 227-268.

Demerouti, E., Bakker, A. B., Nachreiner, F., \& Schaufeli, W. B. (2001). The job demandsresources model of burnout. Journal of Applied Psychology, 86, 499-512. https://doi. org/10.1037//0021-9010.86.3.499.

Desrumaux, P., Lapointe, D., Ntsame Sima, M., Boudrais, J.-S., Savoie, A., \& Brunet, L. (2015). The impact of work demands, climate, and optimism on wellbeing and distress at work: What are the mediating effects of basic psychological need satisfaction? Revue européenne de spychologie appliquée, 65, 179-188. https://doi.org/10.1016/j.erap.2015.06.003.

Fernet, C., Austin, S., Trépanier, S.-G., \& Dussault, M. (2013). How do job characteristics constibute to burnout? Exploring the distinct mediating roles of perceived autonomy, competence, and relatedness. European Journal of Work and Organizational Psychology, 22, 123-137. https://doi. org/10.1080/1359432X.2011.632161.

Fernet, C., Guay, F., Senécal, C., \& Austin, S. (2012). Predicting intraindividual changes in teacher burnout: The role of perceived school environment and motivational factors. Teaching and Teacher Education, 28, 514-525. https://doi.org/10.1016/j.tate.2011.11.013. 
Friedman, I. A. (1995). Student behavior patterns contributing to teacher burnout. Journal of Educational Research, 88, 281-333. https://doi.org/10.1080/00220671.1995.9941312.

Guarino, C. M., Santibañez, L., \& Daley, G. A. (2006). Teacher recruitment and retention: A review of the recent empirical literature. Review of Educational Research, 76, 173-208. https://doi. org/10.3102/00346543076002173.

Hakanen, J. J., Bakker, A. B., \& Schaufeli, W. B. (2006). Burnout and work engagement among teachers. Journal of School Psychology, 43, 495-513. https://doi.org/10.1016/j.jsp.2005.11.001.

Hargreaves, A. (2003). Teaching in the knowledge society: Education in the age of insecurity. Milton Keynes: Open University Press.

Hong, J. Y. (2010). Pre-service and beginning teachers' professional identity and its relation to dropping out of the profession. Teaching and Teacher Education, 26, 1530-1543. https://doi. org/10.1016/j.tate.2010.06.003.

Hu, L. T., \& Bentler, P. M. (1999). Cutoff criteria for fit indexes in covariance structure analysis: Conventional criteria versus new alternatives. Structural Equation Modeling: A Multidisciplinary Journal, 6, 1-55. https://doi.org/10.1080/10705519909540118.

Ingersoll, R. M. (2001). Teacher turnover and teacher shortages: An organizational analysis. American Educational Research Journal, 38, 499-534. https://doi.org/10.3102/00028312038003499.

Johnson, S., Cooper, C., Cartwright, S., Donald, I., Taylor, P., \& Millet, C. (2005). The experience of work-related stress across occupations. Journal of Managerial Psychology, 20, 178-187. https:// doi.org/10.1108/02683940510579803.

Klassen, R., \& Chiu, M. M. (2010). Effects on teachers' self-efficacy and job satisfaction: Teacher gender, years of experience, and job stress. Journal of Educational Psychology, 102, 741-756. https://doi.org/10.1037/a0019237.

Klassen, R., Wilson, E., Siu, A. F. Y., Hannok, W., Wong, M. W., Wongsri, N., et al. (2013). Preservice teachers' work stress, self-efficacy, and occupational commitment in four countries. European Journal of Psychology of Education, 28, 1289-1309. https://doi.org/10.1007/s1021 2-012-0166-x.

Köber, T., Risberg, T., \& Texmon, T. (2005). Hvor jobber førskolelærere og lærere? In Utdanning (pp. 232-253). Oslo: Statistics Norway.

Kokkinos, C. M. (2007). Job stressors, personality and burnout in primary school teachers. British Journal of Educational Psychology, 77, 229-243. https://doi.org/10.1348/000709905X90344.

Kyriacou, C. (1987). Teacher stress and burnout: An international review. Educational Research, 29, 146-152. https://doi.org/10.1080/0013188870290207.

Kyriacou, C. (2001). Teacher stress: Directions for future research. Educational Review, 53, 27-35. https://doi.org/10.1080/00131910120033628.

Kyriacou, D., \& Sutcliffe, J. (1979). A note on teacher stress and locus of control. Journal of Occupational Psychology, 52, 227-228. https://doi.org/10.1111/j.2044-8325.1979.tb00456.x.

Leung, D. Y. P., \& Lee, W. W. S. (2006). Predicting intention to quit among Chinese teachers: Differential predictability of the component of burnout. Anxiety, Stress, \& Coping, 19, 129-141. https ://doi.org/10.1080/10615800600565476.

Lindqvist, P., \& Nordänger, U. K. (2006). Who dares to disconnect in the age of uncertainty? Teachers' recesses and "off-the-clock" work. Teachers and Teaching: Theory and Practice, 12, 623-637.

Liu, S., \& Onwuegbuzie, A. J. (2012). Chinese teachers' work stress and their turnover intention. International Journal of Educational Research, 53, 160-170. https://doi.org/10.1016/j. ijer.2012.03.006.

Lundberg, U. (2003). Psychological stress and musculoskeletal disorders: Psychobiological mechanisms. Lack of rest and recovery greater problem than workload. Lakartidningen, 100(21), 1892-1895.

Mahoney, J. L., Schweder, A. E., \& Stattin, H. (2002). Structured after-school activities as a moderator of depressed mood for adolescents with detached relations to their parents. Journal of Community Psychology, 30, 69-86. https://doi.org/10.1002/jcop.1051.

Maslach, C. (2003). Job burnout: New directions in research and intervention. Current Directions in Psychological Science, 12, 189-192. https://doi.org/10.1111/1467-8721.01258.

Maslach, C., Jackson, S. E., \& Leiter, M. P. (1996). Maslach burnout inventory manual (3rd ed.). Mountain View, CA: CPP Inc.

McDonald, D. (1999). Teacher attrition: A review of literature. Teaching and Teacher Education, 15, 835-848. https://doi.org/10.1016/S0742-051X(99)00031-1. 
Montgomery, C., \& Rupp, A. A. (2005). Meta-analysis for exploring the diversity causes and effects of stress in teachers. Canadian Journal of Education, 28, 458-486. https://doi.org/10.2307/41264 79.

Pines, A., \& Aronson, E. (1988). Career burnout. causes and cures. New York: The Free Press.

Ritvanen, T., Louhevaara, V., Helin, P., Väisänen, S., \& Hänninen, O. (2006). Responses of the automatic nervous system during periods of high and low work stress in younger and older female teachers. Applied Ergometrics, 37, 311-318. https://doi.org/10.1016/j.apergo.2005.06.013.

Rosenberg, M. (1977). Contextual dissonance effects: Nature and causes. Psychiatry, 40, 205-217.

Rosenberg, M. (1979). Conceiving the self. New York: Basic Books.

Sahlberg, P. (2010). Rethinking accountability in a knowledge society. Journal of Educational Change, 11, 45-61. https://doi.org/10.1007/s10833-008-9098-2.

Schaufeli, W. B., \& Bakker, A. B. (2010). Defining and measuring work engagement. In A. Bakker \& P. Leiter (Eds.), Work engagement. A handbook of essential theory and research (pp. 10-24). New York: Psychology Press.

Schaufeli, W. B., Bakker, A. B., \& Salanova, M. (2006). The measurement of work engagement with a short questionnaire. A cross-national study. Educational and Psychological Measurement, 66, 701-716. https://doi.org/10.1177/0013164405282471.

Schwarzer, R., Schmitz, G. S., \& Tang, C. (2000). Teacher burnout in Hong Kong and Germany: A cross-cultural validation of the Maslach burnout inventory. Anxiety, Stress, \& Coping, 13, 309323. https://doi.org/10.1080/10615800701217878.

Scott, C., Stone, B., \& Dinham, S. (2001). I love teaching but.... International patterns of teaching discontent. Education Policy Analysis Archives, 9(28), 1-16.

Shen, X., Yang, Y.-L., Wang, Y., Liu, L., Wang, S., \& Wang, L. (2014). The association between occupational stress and depressive symptoms and the mediating role of psychological capital among Chinese university teachers: A cross-sectional study. BMC Psychiatry, 14, 329. https:// doi.org/10.1186/s12888-014-0329-1.

Shernoff, E. S., Mehta, T. G., Atkins, M. S., Torf, R., \& Spencer, J. (2011). A qualitative study of the sources and impact of stress among urban teachers. School Mental Health, 3, 59-69. https://doi. org/10.1007/s12310-011-9051-z.

Simbula, S., Guglielmi, D., \& Schaufeli, W. B. (2011). A three-wave study of job resources, selfefficacy, and work engagement among Italian schoolteachers. European Journal of Work and Organizational Psychology, 20, 285-304. https://doi.org/10.1080/13594320903513916.

Skaalvik, E. M., \& Skaalvik, S. (2009). Does school context matter? Relations with teacher burnout and job satisfaction. Teaching and Teacher Education, 25, 518-524. https://doi.org/10.1016/j. tate.2008.12.006.

Skaalvik, E. M., \& Skaalvik, S. (2011a). Teacher job satisfaction and motivation to leave the teaching profession: Relations with school context, feeling of belonging, and emotional exhaustion. Teaching and Teacher Education, 27, 1029-1038. https://doi.org/10.1016/j.tate.2011.04.001.

Skaalvik, E. M., \& Skaalvik, S. (2011b). Teachers' feeling of belonging, exhaustion, and job satisfaction: The role of goal structure and value consonance. Anxiety, Stress, \& Coping: An International Journal, 24, 369-385. https://doi.org/10.1080/10615806.2010.544300.

Skaalvik, E. M., \& Skaalvik, S. (2015). Job satisfaction, stress and coping strategies in the teaching profession-What do teachers say? International Education Studies, 8(3), 181-192. https://doi. org/10.5539/ies.v8n3p181.

Skaalvik, E. M., \& Skaalvik, S. (2016). Teacher stress and teacher self-efficacy as predictors of engagement, emotional exhaustion, and motivation to leave the teaching profession. Creative Education, 7, 1785-1799. https://doi.org/10.4236/ce.2016.713182.

Skaalvik, E. M., \& Skaalvik, S. (2017a). Still motivated to teach? A study of school context variables, stress and job satisfaction among teachers in senior high school. Social Psychology of Education, 20, 15-37. https://doi.org/10.1007/s11218-016-9363-9.

Skaalvik, E. M., \& Skaalvik, S. (2017b). Motivated for teaching? Associations with school goal structure, teacher self-efficacy, job satisfaction, and emotional exhaustion. Teaching and Teacher Education, 67, 152-160. https://doi.org/10.1016/j.tate.2017.06.006.

Skaalvik, E. M., \& Skaalvik, S. (2017c). Dimensions of teacher burnout: Relations with potential stressors at school. Social Psychology of Education, 20, 775-790. https://doi.org/10.1007/s1121 8-9391-0. 
Skaalvik, E. M., \& Skaalvik, S. (2017d). Teacher stress and teacher self-efficacy: Relations and consequences. In T. M. McIntyre, S. E. McIntyre, \& D. J. Francis (Eds.), Educator stress: An occupational health perspective (pp. 101-125). Cham: Springer. ISBN 978-3-319-53053-6.

Smithers, A., \& Robinson, P. (2003). Factors affecting teachers' decisions to leave the profession. Liverpool, England: University of Liverpool, Centre for Education and Employment Research, Department for Education and Skills, Research Report RR430. http://dera.ioe.ac.uk/4759/1/ RR430.pdf. Accessed June 2003.

Stoeber, J., \& Rennert, D. (2008). Perfectionism in school teachers: Relations with stress appraisals, coping styles, and burnout. Anxiety, Stress, \& Coping, 21, 37-53. https://doi.org/10.1080/10615 800701742461.

Tabachnick, B. G., \& Fidell, L. S. (2007). Using multivariate statistics. Boston: Pearson/Allyn and Bacon.

Watt, H. M. G., \& Richardson, P. W. (2008). Motivations, perceptions, and aspirations concerning teaching as a career for different types of beginning teachers. Learning and Instruction, 18, 408-428. https://doi.org/10.1016/j.learninstruc.2008.06.002.

Weiss, E. M. (1999). Perceived workplace conditions and first-year teachers' morale, career choice commitment, and planned retention: A secondary analysis. Teaching and Teacher Education, 15, 861879. https://doi.org/10.1016/S0742-051X(99)00040-2.

Einar M. Skaalvik is professor emeritus in educational psychology and is presently affiliated with NTNU Social Research. His research interests are in the areas of motivation, self-concept, self-efficacy, wellbeing, and mental health among students and teachers.

Sidsel Skaalvik is a Professor emerita in special education at the Department of Education at the Norwegian University of Science and Technology. Her research interests are in the areas of reading and learning difficulties, instructional methods, motivation, self-conception, and well-being among both students and teachers. 